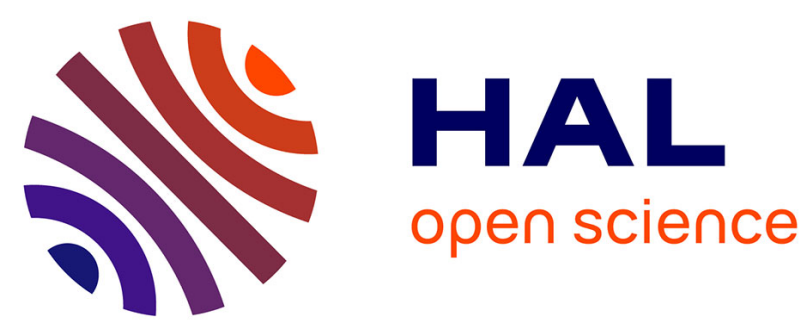

\title{
Inelastic ball-plane impact : an accurate way to measure the normal restitution coefficient
}

\author{
Marc Leconte, Yves Garrabos, Fabien Palencia, Carole Lecoutre-Chabot, \\ Pierre Evesque, Daniel Beysens
}

\section{- To cite this version:}

Marc Leconte, Yves Garrabos, Fabien Palencia, Carole Lecoutre-Chabot, Pierre Evesque, et al.. Inelastic ball-plane impact: an accurate way to measure the normal restitution coefficient. Applied Physics Letters, 2006, 89 (24), 243518 (3 p.). 10.1063/1.2400061 . hal-00123249

\section{HAL Id: hal-00123249 \\ https://hal.science/hal-00123249}

Submitted on 1 Jul 2021

HAL is a multi-disciplinary open access archive for the deposit and dissemination of scientific research documents, whether they are published or not. The documents may come from teaching and research institutions in France or abroad, or from public or private research centers.
L'archive ouverte pluridisciplinaire $\mathbf{H A L}$, est destinée au dépôt et à la diffusion de documents scientifiques de niveau recherche, publiés ou non, émanant des établissements d'enseignement et de recherche français ou étrangers, des laboratoires publics ou privés. 


\section{Inelastic ball-plane impact: An accurate way to measure the normal restitution coefficient}

Cite as: Appl. Phys. Lett. 89, 243518 (2006); https://doi.org/10.1063/1.2400061

Submitted: 29 June 2006 . Accepted: 24 October 2006 . Published Online: 15 December 2006

M. Leconte, Y. Garrabos, F. Palencia, C. Lecoutre, P. Evesque, and D. Beysens

\section{ARTICLES YOU MAY BE INTERESTED IN}

Listening to the coefficient of restitution

American Journal of Physics 45, 41 (1977); https://doi.org/10.1119/1.10904

Listening to the coefficient of restitution and the gravitational acceleration of a bouncing ball American Journal of Physics 71, 499 (2003); https://doi.org/10.1119/1.1524166

Listening to the coefficient of restitution-revisited

American Journal of Physics 69, 301 (2001); https://doi.org/10.1119/1.1326077

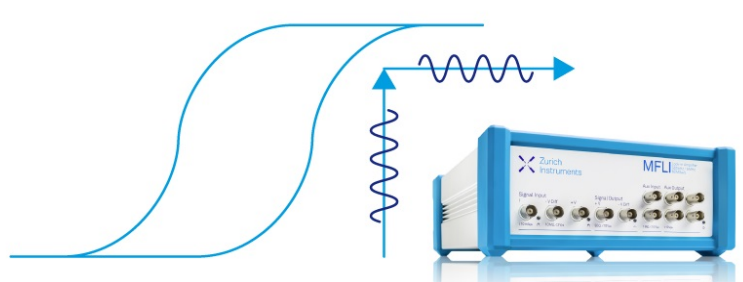

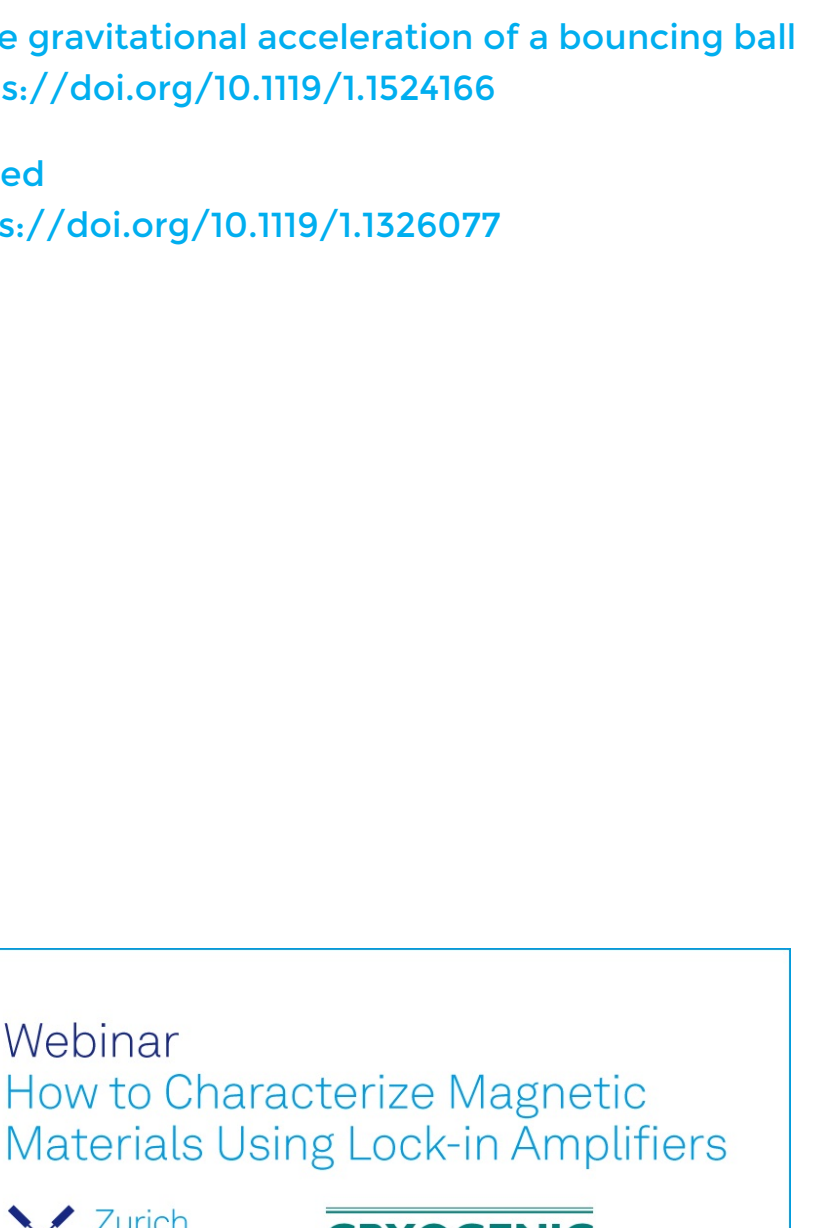

\begin{tabular}{l} 
gravitational acceleration of a bouncing ball \\
s://doi.org/10.1119/1.1524166 \\
s://doi.org/10.1119/1.1326077 \\
Webinar \\
How to Characterize Magnetic \\
Materials Using Lock-in Amplifiers \\
\hline Zurich \\
WroO
\end{tabular}

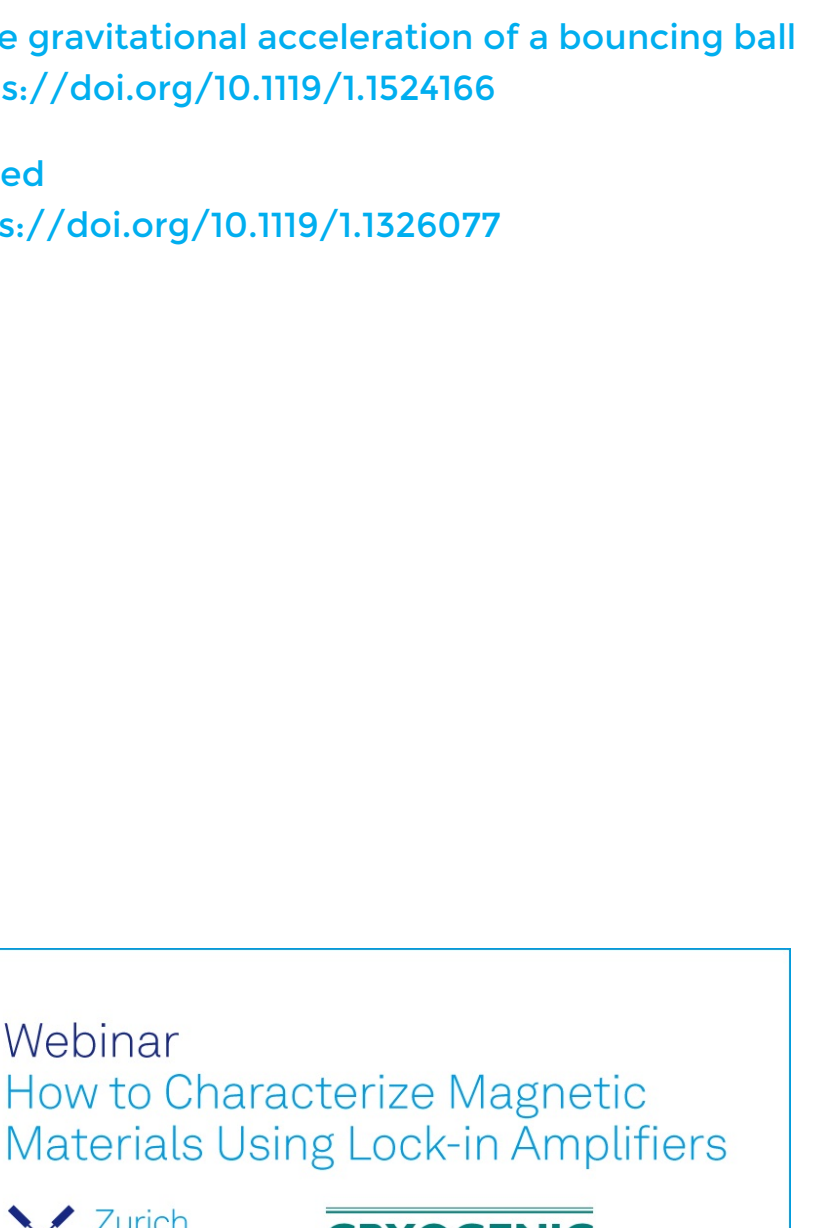

Zurich

Instruments CROGPaic 


\title{
Inelastic ball-plane impact: An accurate way to measure the normal restitution coefficient
}

\author{
M. Leconte \\ Laboratoire MSSMat, École Centrale Paris, UMR 8579 CNRS, 92295 Chatenay-Malabry, France \\ Y. Garrabos, ${ }^{a}$ F. Palencia, and C. Lecoutre \\ ESEME-CNRS, ICMCB UPR 9048 CNRS, 87 av. A. Schweitzer, Université Bordeaux 1, 33608 Pessac \\ Cedex, France \\ P. Evesque \\ Laboratoire MSSMat, École Centrale Paris, UMR 8579 CNRS, 92295 Chatenay-Malabry, France \\ D. Beysens \\ ESEME-CEA, ESPCI, UMR 7636 CNRS, Universités Paris 6 et Paris 7, 10 rue Vauquelin, 75005 Paris, \\ France
}

(Received 29 June 2006; accepted 24 October 2006; published online 15 December 2006)

\begin{abstract}
The authors describe a setup to measure accurately the normal restitution coefficient between a quasiresonant ball and a plane. It uses the fact that the trajectory of a single ball in a cylindrical box with a vibrating wall reduces rapidly to a merely periodic one dimensional dynamics, with little rotation. The ball speed is measured accurately from the time series of impacts. It is also used to study and calibrate a sphere-plane impact sensor. This sensor allows to determine the collision time at a microsecond accuracy and the maximum force applied. The collision is found to obey the Hertz law. (C) 2006 American Institute of Physics. [DOI: 10.1063/1.2400061]
\end{abstract}

When a macroscopic particle collides with a rigid wall or another particle, it suffers a loss of energy, generating heat and deformation. The collision is then called inelastic and it is partly characterized by a normal restitution coefficient computed from the normal velocity before and after the impact. The knowledge of the dependence of this coefficient on the initial velocity of the particle has motivated numerous works to better understand the dynamics of a collision and to improve the modeling and the numerical simulations on granular material. Until now, the measure of restitution coefficient between sphere/sphere or sphere/plate is often performed with a high speed video camera. ${ }^{1}$ This letter is aimed at describing another technique to measure more accurately the normal restitution coefficient between a fixed plane and a moving ball excited by the sinusoidal motion of a piston in a direction perpendicular to the plane. The measurements are based on the observation of the coherent behavior of a ball filling a cylinder closed at the top by a fixed force sensor and at the bottom by the moving piston mechanically linked to a triaxial accelerometer. The schematic drawing of the basic setup is given in Fig. 1. The classical problem of a free bouncing ball on a vibrating piston has been extensively studied under Earth's gravity ${ }^{2}$ for its importance in chaotic dynamics and its link with ergodicity. However, it has been recently revisited considering fast enough excitation in microgravity experiment, ${ }^{3}$ using a closed box where a lid takes a role equivalent to the gravity in the Fermi acceleration mechanism. ${ }^{4}$ In particular, one observes that the ball motion reduces quasi-instantaneously to a one dimensional trajectory in the direction of vibration. This drastic reduction of the phase space is due to the combined effects of the rules of collisions and the existence of the two (fixed and moving) walls that improves the losses in translational degrees of

${ }^{a)}$ Electronic mail: garrabos@icmcb-bordeaux.cnrs.fr freedom. This annihilates the ball rotation and freezes the ball motion in the direction of excitation. Then a resonant behavior of the ball takes place on the longest possible trajectory parallel to the vibration. This particle behavior is synchronized with the piston motion when the amplitude of the vibration is large enough, and the particle/wall impacts occur at periodic instants with a well defined velocity. ${ }^{3}$ Using precise impact time measurements (described below), one can deduce flight times and velocities of the ball before and after successive impacts, thus accurate measurements of the normal restitution coefficients attached to each plane/wall contact can be made. The main advantages of our setup can be seen from the typical results of Fig. 2, which were obtained by using a stainless steel spherical bead of radius $R$ $=1.000 \pm 0.001 \mathrm{~mm}$ and mass $m=(32.67 \pm 0.10) \times 10^{-6} \mathrm{~kg}$. In this freestanding installation, the force sensor works with ball impacts that can produce a high-frequency ringing. Such effects have no influence on our measurements (see below). A significant part of the tests was performed in microgravity during parabolic flights in order to avoid the gravity effect

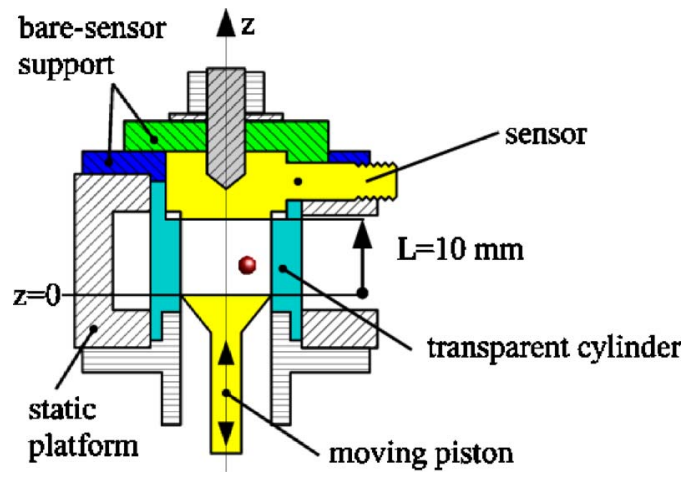

FIG. 1. Experimental setup: Schematic cross section of the cylindrical cell with a force sensor in a freestanding installation. 


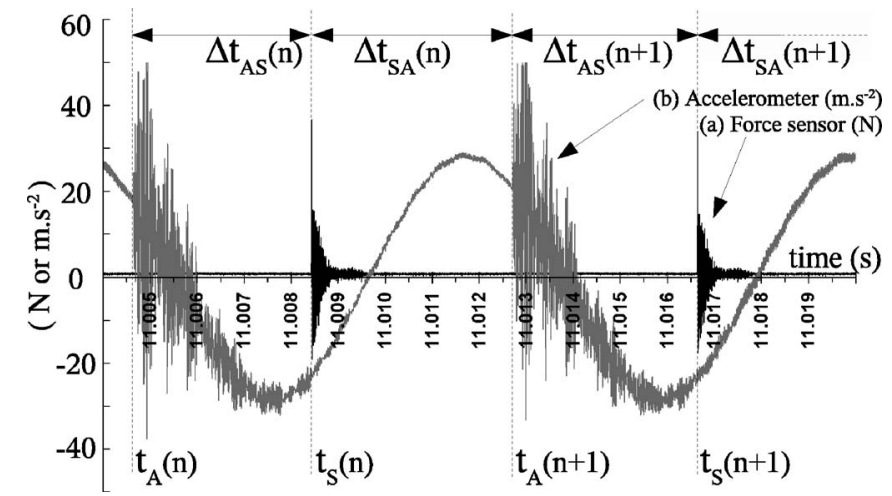

FIG. 2. Experimental signals recorded at $f=100 \mathrm{~Hz}$ and $A_{p}=1 \mathrm{~mm}$ by (a) the force sensor acting as a fixed plane wall and (b) the accelerometer linked to the moving piston (ball radius $R=1 \mathrm{~mm}$ ).

for better control of the uncertainties. Now, the setup can also be used in a " $1 g_{0}$ " environment (with $g_{0}=9.81 \mathrm{~m} / \mathrm{s}^{2}$ ), introducing analytical corrections to treat automatically the ball trajectory in the Earth's acceleration field $g_{0}$.

The ball is free to move in a vertical cylinder of inner diameter $D=12.7 \mathrm{~mm}$ and inner height $H=10.0 \mathrm{~mm}$ (at rest). The bottom wall (i.e., the piston surface) moves sinusoidally according to $A_{p} \sin (\omega t)$. The piston was linked to a magnetic coil which performs a vertical acceleration $-\Gamma_{p} \sin (\omega t), f$ $=\omega / 2 \pi \in[30-140 \mathrm{~Hz}]$ and $\Gamma_{p} \in\left[1-500 \mathrm{~m} / \mathrm{s}^{2}\right]$, with the aid of an electromagnetic shaker. The vertical sinusoidal acceleration is driven with a low-distortion signal generated by the analog output channel of a digital-analog converter. The digital triggering of each sine wave is made at 5000 samples/s $\times 12$ bit resolution. The acceleration of the shaker is measured by using a piezoelectric triaxial accelerometer, recorded at 10 kilosamples $/ \mathrm{s} \times 12$ bit resolution. Moreover, a second acquisition of the vertical acceleration is made at 2 megasamples/s $\times 12$ bits, which allows to accurately detect the impact time with the piston. The maximum amplitude of displacement of the piston is $A_{p}=\Gamma_{p} / \omega^{2}$ $\in[0.1 \mathrm{~mm} ; 1.5 \mathrm{~mm}]$ and the piston's velocity can go up to $1.78 \mathrm{~m} / \mathrm{s} . \Gamma_{p}$ and $f$ are obtained from direct Fourier transform of the acceleration signal while the velocity and displacement of the piston are computed by signal integration. The flat sensing surface of a fixed force sensor closes the box on its top, in front of the moving piston. This top wall is made of stainless steel. The acquisition from the force sensor is also made at 2 megasamples/s $\times 12$ bits, thanks to the same acquisition device, and a $25 \mathrm{~Hz}$ video camera with a $700 \times 500$ pixel resolution is used to observe the bead dynamics and the moving piston. The quasiresonant motion of the bead can be also analyzed and controlled by stroboscopic illumination of the cell at the shaker frequency. The experiment is embedded in an Airbus A300-0G performing parabolas during which the gravity is reduced to $0 \pm 0.05 g_{0}$. Figure 2 shows a typical signal from the force sensor and from the vertical accelerometer when the ball moves in resonance with the piston motion. The latter signal is recognizable from its sinusoid base line and allows one to determine the times of impact with the piston accurately. The signal observed from the sensor after each impact results in a high-frequency ringing, mainly due to beating at 100 and $110 \mathrm{kHz}$, which relaxes within a characteristic time of $200-400 \mu \mathrm{s}$. As the first peak of the fast sensor response contains most of the information concerning the dynamical contact (see below), it

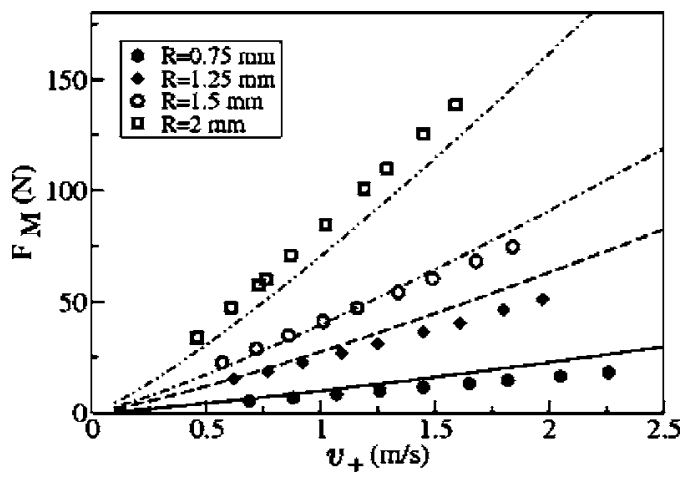

FIG. 3. Ball impact force (in Newtons) measured by the force sensor as a function of the input ball velocity for different ball radii. The curves are expected for Hertz-like behavior (see text).

has been used to study the effect of the impact location, which has been found to be not relevant. In this case, the sensor relaxation time is then much smaller than the smallest period of the vibrating piston, allowing each impact to be detected with good accuracy. As it will be related elsewhere, this setup can be used to calibrate a gauge. Actually, it has been found that the maximum amplitude of the signal is proportionnal to the contact force $F_{M}$. As an example of the efficiency of the setup, we report in Fig. 3 the data obtained with a series of steel spheres of different radii $R$ as a function of the speed $v_{+}$before the collision. The data are compared to predictions with no adjustable parameters by using a Hertzian law of contact, $F_{M}^{\text {Hertz }}=(5 m / 4)^{3 / 5} k^{2 / 5}\left(v_{+}\right)^{6 / 5}$, where $k$ $=2 E \sqrt{R} /\left[3\left(1-\nu^{2}\right)\right]$. Here $E$ and $\nu$ are Young's modulus and Poisson's ratio of the material, respectively: $E=21.6$ $\times 10^{10} \mathrm{~N} / \mathrm{m}^{2}$ and $\nu=0.276$. The ball speed is deduced from the time of flight between the successive impacts with the (bottom) piston and the (top) sensor: $v_{+}=[L-2 R$ $\left.-A_{p} \sin \left(\omega t_{A}(n+1)\right)\right] / \Delta t_{A S}(n)$ (see Fig. 2 for notation). Figure 3 shows the experimental data and theoretical prediction without any adjustable parameters for $F_{M}$ as a function of the ball velocity and for different ball radii. Experimental and theoretical results are in good agreement in the whole range of the velocities investigated. Finally, one can measure discrete values and mean value of the restitution coefficient $\varepsilon$ $=-v_{-} / v_{+}\left[\right.$where $v_{-}=-\left(L-2 R-A_{p} \sin \left(\omega t_{A}(n+1)\right)\right) / \Delta t_{S A}(n)$ is the output ball speed]. Figure 4 displays the mean value of the discretized restitution coefficient as a function of the

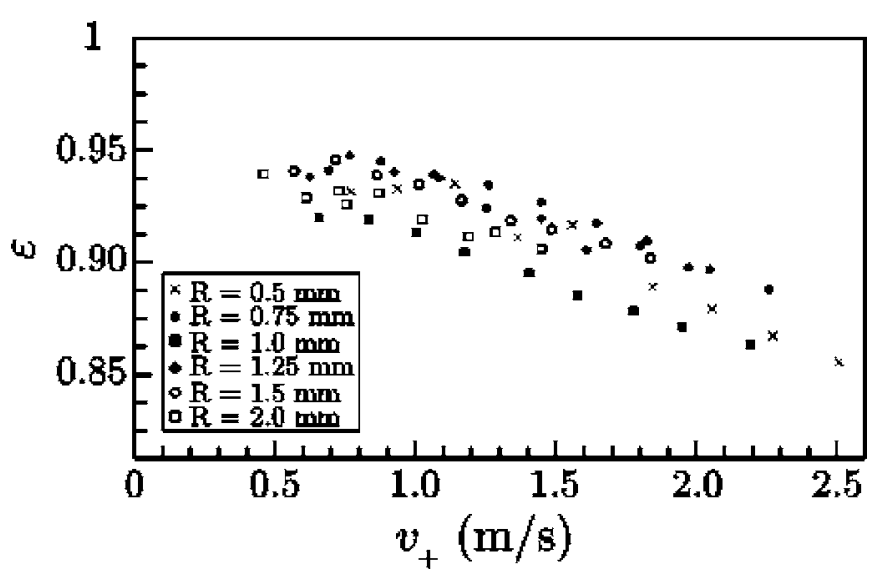

FIG. 4. Measured mean value of the normal restitution coefficient as a function of the input ball velocity for different ball radii. 
mean value of the discretized ball velocity for balls with different radii. The precision of our data is greater than any other classical method used to measure similar impact parameters due to the 2 megasamples/s sampling rate. One notes that $\varepsilon$ decays slowly and linearly with the increase of velocity from nearly 0.95 to 0.88 and that the diameter of the particle seems to have a nonsignificant role on $\varepsilon$. This is currently studied in detail to measure the normal restitution coefficient between the ball and the plane of different materials, now using an improved setup where the force sensor is covered by an exchangeable massive cap. It permits, for example, the study of plasticity ${ }^{5}$ at large speed. Moreover, the present experiment reveals that plasticity occurs at larger speeds due to the dynamical improvement of elastic properties of materials. ${ }^{4}$

In conclusion, we have presented a method to measure the normal coefficient of restitution between a ball and a plane which uses a closed box with a moving piston. Accurate results are obtained, thanks to the geometrical configuration, the resonance, and the precision of impact detection. Inversely, the setup can be used to calibrate and qualify gauges accurately. It has been used on a force sensor covered by a cap, whose domain of use has been extended to analyze much shorter times and fast collisions. The variations of the coefficient of restitution of a sphere with a plane has been studied as a function of the ball speed for different sphere diameters and exhibiting small variation, $\varepsilon=0.9-0.95$. Fi- nally, our setup opens a route to produce basic understanding in mechanical alloying, high-energy ball milling, and more generally, in technological processes involved in mechanical material processing.

This work has benefited from A300 Zero-G airplane campaigns and was supported by the Centre National d'Etudes Spatiales and the European Space Agency. The authors gratefully acknowledge Novespace and Centre d'Essais en Vol teams for their kind technical assistance.

${ }^{1}$ L. Labous, A. D. Rosato, and R. N. Dave, Phys. Rev. E 56, 005717 (1997); M. Y. Louge and M. E. Adams, ibid. 65, 021303 (2002); H. King, R. White, I. Maxwell, and N. Menon, e-print cond-mat/0209490, and references therein.

${ }^{2}$ N. B. Tuffilaro and A. M. Albano, Am. J. Phys. 54, 939 (1986); T. M. Mello and N. B. Tuffilaro, ibid. 55, 316 (1987); R. L. Zimmerman, ibid. 56, 1147 (1988); P. Boissel, Bulletin de l' Union des Physiciens 86, 217 (1992) [in French].

${ }^{3}$ P. Evesque, F. Palencia, C. Lecoutre-Chabot, D. Beysens, and Y. Garrabos, ISPS 2004, Toronto, Canada, 23-27 May 2004; Microgravity Sci. Technol. XVI-1, 280 (2005); Y. Garrabos, D. Beysens, F. Palencia, C. LecoutreChabot, and P. Evesque, Powders and Grains, edited by R. Garcia-Rojo, H. Herrmann, and S. McNamara (Taylor \& Francis, London, 2005), pp. 1113-1117; Y. Garrabos, P. Évesque, F. Palencia, C. Lecoutre, and D. Beysens, e print cond-mat/0611613.

${ }^{4}$ See for example, A. J. Lichtenberg, M. A. Lieberman, and R. H. Cohen, Physica D 1, 291 (1980), and references therein.

${ }^{5}$ J. M. Lifshitz and H. Kolsky, J. Mech. Phys. Solids 12, 35 (1964). 